Correspondence to: Dr Robert A Werner, Department of Veterans Affairs, Medical Center, 2215 Fuller Road, Ann Arbor, MI 48105, USA.

1 Werner RA, Franzblau A, Albers JW, Buchele H, Armstrong TJ. Use of screening nerve conduction studies for predicting future carpal tunnel syndrome. Occup Environ Med 1997;54:96100.

2 Nathan PA, Meadows KD, Doyle LS. Occupation as a risk factor for impaired sensory conduction of the median nerve at the carpal tunnel. $₹$ Hand Surg 1988;13B(2):167-70.

3 tunnel. F Hand Surg 1988;13B(2):167-70. Nathan PA, Keniston RC, Myers $\mathrm{LD}$, Meadows
$\mathrm{KD}$. Obesity as a risk factor for slowing of sen$\mathrm{KD}$. Obesity as a risk factor for slowing of sen-
sory conduction of the median nerve in industry. A cross sectional and longitudinal study involving 429 workers. F Occup Med 1992;34: 379-83.

4 Nathan PA, Keniston RC, Myers LD, Meadows $\mathrm{KD}$. Longitudinal study of median nerve sensory conduction in industry: relationship to age, gender, hand dominance, occupational hand use, and clinical diagnosis. $f$ Hand Surg 1992;17A:850-7.

5 Nathan PA, Keniston RC, Myers LD, Meadows $\mathrm{KD}$. Predictive value of nerve conduction $\mathrm{KD}$. Predictive value of nerve conduction Nerve 1993;16:1377-82.

\section{Prolonged exposure to an epoxy resin leading to interstitial nephritis}

A 51 year old administrator was transferred with a four week history of malaise and intractable vomiting. His creatinine had deteriorated over 10 days from $343 \mu \mathrm{mol} / 1$ to $524 \mu \mathrm{mol} / \mathrm{l}$. There was no notable personal or family history. He was not taking any medications or herbal remedies. Further questioning showed that over the previous 18 months he had been building his own aeroplane in a large but enclosed aircraft hangar. This involved the use of a blended epoxy resin (SP Ampreg 20) and the associated SP Ampreg 20 standard hardener (3-aminomethyl-3, 5, 5-trimethylcyclohexylamine and 4, 4'- isopropylidenediphenol) (Standard Polymer Systems). Six months previously he had developed severe contact dermatitis which resolved on use of occlusive hand protection.

Physical examination was unremarkable. Urinary analysis showed $850 \mathrm{mg}$ protein/ 24 hours and negative microscopy. Routine immunological tests and ultrasound of the renal tract were normal. Histological examination of a percutaneous renal biopsy showed an interstitial nephritis with lymphocytes, plasma cells, and a few eosinophils. There was mild interstitial fibrosis.

The patient was started on oral prednisolone at $0.5 \mathrm{mg} / \mathrm{kg} /$ day. This was slowly reduced over eight weeks to $10 \mathrm{mg}$ daily and the creatinine improved to $155 \mu \mathrm{mol} / 1 \mathrm{six}$ months later.

We think that this patient developed interstitial nephritis secondary to inhalation of volatile substances associated with the use of an epoxy resin. He had no contact with other chemicals known to cause this disease. $\mathrm{He}$ experienced general malaise which cannot be accounted for by the degree of renal impairment, but is consistent with the systemic effects of resin exposure. Previous severe dermatitis and systemic symptoms had improved with the end of direct contact.

Epoxy resins are formed by the condensation of epichlorohydrin and a diphenol in the presence of an alkaline hardener. Allergic illnesses, particularly dermatitis, can be caused either by the resin or the hardening agents. Contact can be direct or by inhalation of volatile hydrocarbons.
Workers chronically exposed to volatile organic solvents have been shown to have significantly more protein in their urine than controls. ${ }^{2}$ Cases of acute interstitial nephritis have been reported associated with volatile hydrocarbons. Two were related to chronic exposure in glue sniffers ${ }^{34}$ and one after a single episode of exposure to polyamide epoxy high gloss paint fumes. ${ }^{5}$

Interstitial nephritis is a pathological entity characterised by a mononuclear cell infiltrate of the renal tubular interstitium. Although lymphocytes predominate eosinophilia can occur particularly when drugs are identified as the cause. Clinically the picture is of an acute decline in renal function which can be associated with heavy proteinuria and peripheral oedema. Improvement often occurs after removal of the offending agent, but uncontrolled observations suggest that moderate doses of corticosteroids hasten recovery. Recovery should be complete although evidence of interstitial fibrosis at biopsy is associated with a poorer outcome.

IAN D DITTMER ALISON J ARMITAGE

The Richard Bright Renal Unit, Southmead Hospital, Westbury-on-Trym, Bristol BS10 5NB, United Kingdom

Correspondence to: Dr Ian D Dittmer, The Richard Bright Renal Unit, Southmead Hospital, Westburyon-Trym, Bristol BS10 5NB, UK.

1 Ellenhorn MJ, Barceloux DG. Epoxy resins, Chapter 36. In: Ellehorn MJ, Barceloux DG, eds. Medical toxicology: diagnosis and treatment of human poisoning. New York: Elsevier, 1988;997-9.

2 Askergren A, Allgen L-G, Karlsson C, Lundberg I, Nyberg $E$. Studies on kidney function in subjects exposed to organic solvents. Acta Med Scand 1981;209:479-83.

3 Russ G, Clarkson AR, Woodroffe AJ, Seymour AK, Cheng AKP. Renal failure secondary to "glue sniffing". Med ₹ Aust 1981;2:121-2.

4 Taverner D, Harrison GJ, Bell GM. Acute rena failure due to interstitial nephritis induced by "glue-sniffing" with subsequent recovery. Scot Med $\mathcal{F} 1988 ; 33: 246-7$.

5 Gould DB, Williams JW. Acute interstitial nephritis. $\mathcal{F} A M A$ 1970;238:1628-9.

\section{BOOK REVIEWS}

Screening and surveillance of workers exposed to mineral dusts. Author/editor: G R WAGner. (Pp 68; Price £15) 1996. Geneva: World Health Organisation. ISBN: 92-4-154498-8.

This is a short booklet on an important topic. It is based on contributions made by some two dozen experts participating in a World Health Organisation (WHO) meeting focusing on asbestos, crystalline silica, and coal mine dusts. It aims to be a step by step approach to the development of programmes particularly for developing countries, where "... effective measure are not taken because of a lack of awareness of the problem."

The reader may well wonder whether there still exist countries in which, even where multinational giants are not involved either in financial or advisory roles, management is sophisticated enough to have mastered mining and fibre processing technology and yet has succeeded in remaining ignorant of dust diseases? (For that matter, is it too nihilistic to think that where the infrastructure for dust control is absent, that it will be unlikely that the facilities recommended by WHO would be available, and if they were, whom would they benefit?) In the introductory chapter, medical screening is presented as an integral part of a disease prevention programme, intended to detect disease in its preclinical phase at a stage when its progression can be reversed. Surveillance is defined as the the study of trends and distribution of disease incidence through the systematic collection, analysis, and evaluation of morbidity and mortality reports and other data. To it the authors add the requirements for reporting findings, and for intervention to prevent disease.

As a test of the recommendations of the committee, consider the case of asbestos workers, where the hygiene standard set to protect workers remains to be evaluated. Further, as the author notes, there is uncertainty about the natural history of asbestosis so that we do not know whether it can be detected at a stage where further progression will not occur if exposure ceases.

This was recognised in the discussions leading up to the United Kingdom 1969 Asbestos Regulations. The inadequacy of statutory medical examinations as then practised and understood was recognised. In their place, Lloyd Davies was able to obtain agreement for the need for a national longitudinal survey of asbestos workers, by a few dedicated physicians, that standardised the medical, radiological, and physiological investigations. As the examinations were primarily for research purposes and for the indirect measures of the effectiveness of the regulations or their implementation, and could not be shown to benefit individual workers at risk, it was agreed that participation should be voluntary for workers, but mandatory for employers to permit examination. In parallel, measures of environmental exposure began to be collected, and cancer morbidity and mortality registers were established.

Other times, other ways. Somewhat belatedly, the European Community woke up, and despite the fact that clinical benefit to individual workers had still not been shown, and in the absence of advance in treatment of any of the asbestos diseases since 1969, directed that asbestos workers shall be compulsorily examined. According to this WHO report (annexe 2), United Kingdom asbestos workers currently undergo primarily a screening programme with some surveillance. The target of the programme it declares is to detect asbestosis and pleural changes. The two yearly medical examination should include: medical and occupational histories; chest $x$ ray films; and pulmonary function tests (forced expiratory volume in one second and forced vital capacity $\left(\mathrm{FEV}_{1}\right.$, and FVC). In fact, Health and Safety Executive regulations implementing the European Directive do not prescribe the details of examination, they are left to the discretion and clinical judgement of the appointed doctor. (The clock, incidentally having been quietly turned back to the appointed doctor system, largely eradicated on 1 February 1973).

The WHO states that the effectiveness of the United Kingdom programme will be assessed by published statistics. Annual audit of the mesothelioma register is certainly published, and there has been a mortality analysis of subjects on the asbestos register, but 
contrary to what the reader might understand from the WHO account, there is no analysis of clinical, radiological, or physiological data. Despite the WHO advocacy of surveillance, the opinions expressed in this booklet on the value of stopping exposure after developing recognisable signs of silicosis, coal workers' pneumoconiosis, coal workers' chronic bronchitis, and chronic airflow limitation, are not much more sanguine than their views on the early management of asbestosis.

The text and the final recommendations contain several inconsistencies. For example to the question: "what is the purpose of the programme: screening, surveillance, or both?" the answer given is: "screening and surveillance should be for non-malignant diseases due to exposure to mineral dust". Yet elsewhere they state, under surveillance, that morbidity and mortality reports should be collected and evaluated. As both silica and asbestos exposures are associated with malignancy, and unless the authors subscribe to the asseveration that cancer can only occur when parenchymal fibrosis is present, then why not monitor cancer morbidity?

They conclude their booklet much as they start, with the truism that disease prevention is a matter of the effective engineering control of exposure. In the case of agents the natural history of whose non-malignant diseases is uncertain, and which possess carcinogenic potential, then the first essential is to keep exposures to as low as is reasonably practicable and certainly they should not exceed the hygiene standard. Where the hygiene standard has never been adequately established, then there is the case for evaluating it by a prospective study of a population large enough to provide adequate power for measuring the residual hazard with a high degree of confidence. Surely medical surveillance requires to be conducted in parallel with environmental monitoring to produce doseresponse relations for the various effects of the dusts, yet the text is silent on the subject of dust measurement.

This booklet provides excellent guidance on the design and evaluation of questionnaires, and on the limitations of radiology and physiology in the monitoring of the progression of disease. It sets the conditions to be considered before a screening test is adopted, that in practice rules them all out. It disarmingly acknowledges the insensitivity of tests to detect disease, and their inability to detect early trivial reversible effects. As for the value of findings from screening in directing medical intervention, the limitations of prophylactic or therapeutic treatments of silicosis, asbestosis, and the various respiratory disorders of coal workers are virtually nil. (Belief in the inhalation of certain other dusts as sovereign specifics for silicosis and anthracosilicosis, seems to be at present dead.)

This booklet has the hallmarks of the report of a committee activity, in which the editor, out of respect, has included the views of its members even where they are apparently contradictory. With the collection of contributors listed, there is inevitably a lot of good material in this publication. However, I find it difficult to believe that certain members will be any happier with this booklet than some of its potential readers.
Topics in Environmental Epidemiology. Eds: K STEENLAND, D A SAVITZ. (Pp 320; $£ 37.50)$. 1997. Oxford: Oxford University Press. ISBN: 0195095642.

I am not sure that environmental epidemiology is a new subject: perhaps it just seems that way. Certainly during the past 10 years or so epidemiologists have focused upon environmental exposures to a range of substances and have reported several significant associations. This has provoked brisk debate with a notable polarisation of views. In the air pollution field the debate has descended to personal abuse, the correspondence columns of journals being filled with accusation and counter accusation. For the non-expert this has been perplexing; for the regulatory toxicologist trying to use the results of epidemiological studies to devise environmental standards for pollutants, this has been a nightmare. This new book helps to clarify the picture and should be read carefully by all those involved in the field both as practitioners of environmental epidemiology and as users of the results.

The book contains 15 chapters: two introductory ones dealing with study design and with meta-analysis, the remainder dealing with individual problems in detail. The authors of the chapter on study design (Steenland and Deddens) deal well with the problems of confounding and causality. Clusters are considered in detail and a handsome list of reasons why most studies of clusters of diseases are "unlikely to lead to discovery of environmental causes" is provided. This is sobering; and yet-as the authors point out the identification of clusters has been the key to the identification of several important cause and effect relations. Deciding on the importance of single cluster still seems tricky. The chapter on metaanalysis and risk assessment is well written and important. Meta-analysis is used increasingly often in environmental epidemiology and it is essential to understand, intuitively or otherwise, whether it can be satisfactorily applied to given groups of studies. The authors deal with difficult questions including the advisability of forcing plots of standardised mortality ratio (SMR) versus exposure through the origin. The authors come to a clear conclusion: use a linear approach (through zero) unless there are good reasons for not doing so. An important exception to the use of relative risk models is provided: cases where the background risk is very low-for example, mesotheliomata. In providing an example (airborne nickel and lung cancer) the authors introduce the concept of "index of precision": I have not seen this used in air pollution studies. The index (ratio of (SMR-1) to the (upper confidence interval of SMR-1)) allows a judgement of the suitability of studies for risk estimation.

The chapters dealing with specific problems are all interesting. Three deal with outdoor air pollution: Borja-Aburto and Loomis on ozone, Dockery and Pope on particles, Sunyer on nitrogen dioxide. These chapters should be studied by anybody dealing with these problems: the conclusions may be unexpected! For particles the case for effects on health is made; for nitrogen dioxide it is not, for ozone it is uncertain. Space here does not allow for detailed comment but these conclusions are themselves causes for concern in view of the possible effects of air pol- lutants on the health of very many people and the costs of abatement strategies especially in developing countries.

Bellinger and Joel Schwartz have contributed a chapter on effects of lead in children and adults. In a detailed account the authors raise the important and often ignored problem of difference between confounding and effect modification. Confounding can be dealt with statistically; effect modification is more difficult to assess.

In conclusion, this is an excellent book dealing with an important and difficult area. Graduate students following masters courses in environmental epidemiology, those doing doctoral theses in the area, and all those who use the results of such techniques should regard it as required reading.

R I MAYNARD

Occupational, Industrial and Environmental Toxicology, 1st Edition. Eds: M I GREENBERG, R J HAMIITON, S D PHILIIPS. (Pp 600; £64.00). 1997. St Louis: Mosby Year Book Publications. ISBN: 0-8151-3929-2

This is the first edition of a new American textbook and is unlike any other current textbook of toxicology. The editors have drawn together a team of authors, predominantly from the United States, to rewrite Ramazzini: they have succeeded to a greater extent than I would have thought possible. The book is large, more than 600 pages, enlivened by not always appropriate photographs and a lot of common sense. Instead of discussing problems compound by compound the book proceeds occupation by occupation. Thus, athletes, exterminators (rat catchers), florists and groundskeepers, mechanics, pediatric laborers (children not paediatricians), and zookeepers join the familiar ranks of plumbers, coal miners, hairdressers, and drycleaners. This is an extraordinary coverage ( 37 separate chapters: 1 to each occupationa group) and some repetition has been unavoidable. This probably does not matter as most readers will turn up specific chapters rather than reading cover to cover. The style is readable but rather light weight in places. The authors are often very definite about problems on which consensus has not yet been reached. For example, are we sure that chronic OP toxicity (mixed motor and sensory neuropathy) can follow "minimal exposures that required no treatment"? The chapter on military personnel interested me. An excellent discussion is provided of many problems: did you know that "snipes" are naval boiler technicians and that they see little daylight on United States naval vessels? Clausewitz is quoted on the "fog" and "friction" of war. This is important and civilian commentators forget that during war, in the words of Clausewitz, "Everything in war is simple, but the simplest thing is difficult". The section on chemical weapons is odd. The Readers' Digest is quoted on new Russian chemical weapons including "Novichok" although the identity and effects of this compound are not revealed.

Chapters on outdoor and indoor air pollution are provided. These are up to date and clear. In indoor air pollution a useful subsection on behavioural syndromes (sick building 